\title{
Seminal plasma improves cryopreservation of Iberian red deer epididymal sperm
}

\author{
Felipe Martínez-Pastor ${ }^{\mathrm{a}, \mathrm{b}}$, Luis Anel ${ }^{\mathrm{a}, *}$, Camino Guerra ${ }^{\mathrm{a}}$, Mercedes Álvarez ${ }^{\mathrm{a}}$, \\ Ana J. Soler ${ }^{\mathrm{b}}$, J. Julián Garde ${ }^{\mathrm{b}, \mathrm{c}}$, César Chamorro ${ }^{\mathrm{d}}$, Paulino de Paz ${ }^{\mathrm{d}}$ \\ ${ }^{a}$ Reproducción Animal y Obstetricia, University of León, 24071 León, Spain \\ ${ }^{\mathrm{b}}$ Grupo de Biología de la Reproducción, Instituto de Investigación en Recursos Cinegéticos (IREC), \\ UCLM-CSIC-JCCM. Campus Universitario, 02071 Albacete, Spain \\ ${ }^{\mathrm{c}}$ Instituto de Desarrollo Regional (IDR), Seccíon de Recursos Cinegéticos y Ganaderos, UCLM, \\ Campus Universitario, 02071 Albacete, Spain \\ d Biología Celular y Anatomía, University of León, 24071 León, Spain
}

Received 20 December 2005; received in revised form 28 March 2006; accepted 10 April 2006

\begin{abstract}
We tested the protective action of seminal plasma on epididymal spermatozoa from Iberian red deer, especially considering cryopreservation, as a means for germplasm banking improvement. We obtained seminal plasma by centrifuging electroejaculated semen, and part of it was thermically inactivated (denatured plasma; $55^{\circ} \mathrm{C} 30 \mathrm{~min}$ ). Epididymal samples (always at $5{ }^{\circ} \mathrm{C}$ ) were obtained from genitalia harvested after regulated hunting, and pooled for each assay (five in total). We tested three seminal plasma treatments (mixing seminal plasma with samples 2:1): no plasma, untreated plasma and denatured plasma; and four incubation treatments: $32{ }^{\circ} \mathrm{C} 15 \mathrm{~min}, 5^{\circ} \mathrm{C} 15 \mathrm{~min}, 5^{\circ} \mathrm{C} 2 \mathrm{~h}$ and $5{ }^{\circ} \mathrm{C} 6 \mathrm{~h}$. After each incubation, samples were diluted 1:1 with extender: Tes-TrisFructose, $10 \%$ egg yolk, $4 \%$ glycerol; equilibrated for $2 \mathrm{~h}$ at $5{ }^{\circ} \mathrm{C}$, extended down to $10^{9} \mathrm{spz} . / \mathrm{mL}$ and frozen. Sperm quality was evaluated before 1:1 dilution, before freezing and after thawing the samples, assessing motility (CASA) and viability (percentage of viable and acrosome-intact spermatozoa; PI/PNA-FITC and fluorescent microscopy). Plasma treatment, both untreated and denatured, rendered higher viability before freezing and higher results for most parameters after thawing. The improvement was irrespective of incubation treatment, except for viability, which rendered slightly different results for untreated and denatured plasma. This may be due to the presence of thermolabile components. We still have to determine the underlying mechanisms involved in this protection. These results might help to improve the design of cryopreservation extenders for red deer epididymal sperm.
\end{abstract}

(C) 2006 Published by Elsevier Inc.

Keywords: Red deer; Epididymal sperm; Seminal plasma; Cryopreservation; Wildlife preservation

\section{Introduction}

Conservation of biodiversity is a difficult but essential task that must be approached using diverse

\footnotetext{
* Correspondence to: Reproducción Animal, Clínica Veterinaria, Campus de Vegazana, Universidad de León, 24071 León, Spain. Tel.: +34 987291 320; fax: +34987291320.

E-mail address: dsalar@unileon.es (L. Anel).
}

strategies. One of the most promising ones is the use of artificial reproductive techniques and germplasm banks, which provide flexible means of management, and allow to indefinitely store genetic material from whole populations [1]. However, obtaining germplasm from wild animals is generally problematic. Thus post-mortem collection - either from hunted or accidentally killed animals - constitutes the best source of germplasm, especially in areas of regulated hunting. 
Post-mortem semen samples are obtained from the cauda epididymis, where mature spermatozoa in the male genital tract are stored. However, it has been shown that the fertility of epididymal spermatozoa diminishes notably if they are submitted to stressing conditions during the cryopreservation process [2], and there is evidence that sperm DNA is altered in this situation [3]. Although spermatozoa from the cauda epididymis have been compared to ejaculated spermatozoa in terms of functionality and fertility [4], there are many differences, the most important being the different environment surrounding them: epididymal fluid vs. seminal plasma. Seminal plasma is known to exert many effects on spermatozoa, many of them by the direct action of seminal plasma proteins [5-10]. Some of these effects are negative for sperm storage and cryopreservation; thus, Dott et al. [11] found that the incubation of epididymal spermatozoa in seminal plasma was detrimental for survival (dog, ram and bull). These effects are due to a capacitation-inducing effect of the seminal plasma in many species $[6,7,12$ 16]. Moreover, a recent study on the addition of bull seminal plasma to African buffalo epididymal sperm before cryopreservation [17] reported negative results. We must consider that this effect could be due to the enhancing effect of some bovine seminal plasma proteins on capacitation [6], or to a species effect, expressed through a differential sensinivity to the seminal plasma from a different species. Besides, Tecirlioglu et al. [18] found that the addition of seminal plasma to mouse epididymal sperm decreased motility and prevented fertilization.

Nevertheless, seminal plasma has shown positive effects in many studies, both on washed ejaculated spermatozoa and epididymal spermatozoa. In contrast to the capacitating action of some proteins, others regulate sperm function, including suppression of capacitation and acrosome reaction [5,10,19-22]. Moreover, seminal plasma proteins modulate the interaction of spermatozoa with the female genital tract and exert an immunosuppressive action [20,22-27]. Furthermore, it has been demonstrated that seminal plasma improves, and even reverses, cold shock in washed ejaculated spermatozoa from ram $[8,28]$, and also cryopreservation results in this species [29]. Fertility trials have shown that ovine AI results can be improved by addition of seminal plasma, both with cooled [30] and cryopreserved semen [31]. Other beneficial effects of seminal plasma supplementation have been noted in bovine [32], boar [21,33] and human semen [34-37].

Apart from the effect of proteic factors on sperm functions, the beneficial effect of seminal plasma is due to the presence of reactive oxygen species (ROS) scavengers, not only enzymatic (superoxide dismutase, catalase, glutation peroxydase) but also non-enzymatic ( $\alpha$-tocopherol, ascorbic acid, glutation, etc.) [36-46]. Although it has been demonstrated that the epididymis possesses an antioxidant system [47], the low volume of epididymal fluid and the high dilution undergone by epididymal spermatozoa during the collection process could increase their vulnerability to ROS, whereas whole semen might provide a more efficient antioxidant environment, due to the secretions of the accessory sex glands [44,45]. In fact, Braun et al. [48] showed that flushing and storing epididymal spermatozoa with seminal plasma was beneficial for motility.

The objective of the present study is to evaluate the effect of seminal plasma on epididymal sperm obtained from Iberian red deer, especially during the cryopreservation process. This species has a high value in Spain, both ecological and economical, being the most appreciated hunting species. Creation of germplasm banks would greatly enhance management of these populations and preserve its genetic wealth, threatened by inbreeding and hybridization [49]. In this case, a major source of sperm for germplasm banking consists on post-mortem epididymal samples from controlled hunting. However, although many studies on cryopreservation of post-mortem sperm samples from red deer have been carried out [50-54] and successful pregnancies have been achieved [55,56], there are still many improvements to accomplish on the cryopreservation and application of these samples. Indeed, several studies on this species have shown important loss of quality pertaining manipulation and cryostorage of epididymal samples [2] and, as indicated above, Esteso et al. [3] showed that these changes may involve DNA damage. Since this could be caused by the lack of protection of epididymal samples, quality may be better preserved treating the samples with appropriate media, such as seminal plasma.

Nevertheless, there is a general concern on the risk of disease transmission that any assisted reproductive technique conveys $[57,58]$. Use of seminal plasma from one animal to treat the washed or epididymal spermatozoa of another could incur in contamination with pathogens, especially in wild or half-domesticated species, which cannot be submitted to veterinary control as strictly as the domesticated ones. Another drawback from using seminal plasma is the variability between subjects and collecting seasons. Many studies have demonstrated that seminal plasma composition and protective ability vary not only between individuals of 
different fertility [59,60], but also between periods of the year in seasonal breeders (such as cervids living in temperate climates) $[61,62]$. Thus, the research lines aimed to determine the beneficial action of seminal plasma on washed or epididymal sperm should try to identify its key components and use them (obtained from non-animal sources) to improve preservation media, rather than using the seminal plasma itself. However, seminal plasma, once stated its quality and sanitary condition, could be used to improve the cryopreservation of samples from endangered species or valuable individuals.

In this experiment, we supplemented epididymal samples with seminal plasma (untreated and heat treated) obtained by electroejaculation of red deer stags, and applied several incubation treatments (different temperatures and times). The use of different incubation treatments was included in order to enhance the detection of differences between plasma treatments and to help to identify possible protective mechanisms. We intend to determine if seminal plasma would improve epididymal sperm cryopreservation, which may eventually help to enhance current protocols for red deer and similar species.

\section{Materials and methods}

All chemicals were of AnalR grade, and acquired from Sigma (The Netherlands), except otherwise stated.

\subsection{Experimental protocol}

Selected epididymal samples (at least $50 \%$ motile sperm) were pooled to increase available volume. A factorial design $(3 \times 4)$ was followed in order to test the effect of seminal plasma and incubation treatments on epididymal sperm. Each pool was split into three, and two of the aliquots were diluted (1:2) with untreated seminal plasma and denatured seminal plasma, respectively. Then, each aliquot was divided into four and each submitted to a different incubation treatment: $32{ }^{\circ} \mathrm{C}$ for $15 \mathrm{~min}$ (water bath), and $5^{\circ} \mathrm{C}$ for $15 \mathrm{~min}, 2 \mathrm{~h}$ and $6 \mathrm{~h}$, respectively. After incubation, each aliquot was analyzed, diluted 1:1 with extender, and, after equilibration and final extension, frozen. All the aliquots were also analyzed just before freezing and just after thawing. We performed the following analysis: motility (CASA), and viability (percentage of viable and acrosome-intact spermatozoa). We carried out five replicates, always within the breeding season.

\subsection{Sperm recovery}

Genitalia were collected from 37 Iberian red deer (Cervus elaphus hispanicus, Helzheimer 1909) harvested in the game reserves of Ancares, Mampodre and Picos de Europa (León, Spain). All the animals were adults and lived in a free-ranging regime. Sample collection was carried out from the second fortnight of September to the first fortnight of November (within the breeding season). Harvest plans followed Spanish Harvest Regulations, Law 4/96 of Castilla y León and Law 19/01 of Extremadura, which conforms to European Union Regulations. Furthermore, species and number of individuals that can be hunted, as well as the exact periods of the year when hunting can take place, are reviewed each year by the Annual Hunting Regulation of the respective regions.

Scrotum, including testicles and epididymes, were removed from the carcass and refrigerated down to $5{ }^{\circ} \mathrm{C}$ as soon as possible. Date and time of death, collection and refrigeration were noted and attached to the corresponding sample. Refrigerated genitalia were sent to our laboratory at the Veterinary Clinic Hospital of the University of León (Spain), arriving within $48 \mathrm{~h}$ postmortem.

Sample manipulation was carried out in a walk-in fridge $\left(5^{\circ} \mathrm{C}\right)$. Testicles with epididymes and vas deferens attached were isolated from the scrotum and other tissues. Epididymes were dissected free from the testicles, and cleaned of connective tissue. To avoid blood contamination, superficial blood vessels were previously cut and their contents wiped out. Season and post-mortem time were attached to each sample. Spermatozoa were collected making several incisions on the cauda epididymis with a surgical blade, and taking the liquid emerging from the cut tubules with the aid of the blade.

An aliquot of each epididymal sample was diluted in PBS (pH 7.4), warmed to $37{ }^{\circ} \mathrm{C}$ and visually assessed for motility (phase contrast microscopy; Nikon Labophot-2 with a warming stage at $37^{\circ} \mathrm{C}$ ). Selected samples (at least $50 \%$ motile sperm) were pooled (always at $5{ }^{\circ} \mathrm{C}$ ), carrying out the protocol described in 2.1. We obtained samples on 5 different days, thus producing five pools. In total, 20 were considered acceptable for the experiment, and each pool included samples from four to six males.

\subsection{Obtaining and processing seminal plasma}

Ejaculates were obtained in September (breeding season) from adult Iberian red deer stags using 
electroejaculation. The animals were housed in a halffreedom regime at the University of Castilla-La Mancha (Albacete, Spain). Before electroejaculation, stags were restrained and anesthetised by intravenous injection of xylacine and ketamine (Rompun ${ }^{\circledR} 2 \%$ and Imalgene $1000^{\mathbb{R}}$ ). Electroejaculation was carried out using a 3-electrode probe $(25 \mathrm{~cm} \times 3 \mathrm{~cm})$, at average values of $4.5 \mathrm{~V}$ and $90 \mathrm{~mA}$. Anesthesia was reverted with yohimbine $0.9 \%$.

Animal handling was performed in accordance with the Spanish Animal Protection Regulation, RD223/ 1998, which conforms to European Union Regulation $86 / 609$.

We centrifuged seminal samples at $600 \times g$ for 15 min, collecting the clear supernatant (seminal plasma). Seminal plasma from several males was mixed, aliquoted and frozen $\left(-80^{\circ} \mathrm{C}\right)$ until use. After thawing, half of the seminal plasma was submitted to a heat treatment $\left(55^{\circ} \mathrm{C}\right.$ for $\left.30 \mathrm{~min}\right)$ and then transferred to ice for cooling, in order to inactivate heat-labile factors [63] (denatured seminal plasma).

The effect of heat inactivation of seminal plasma was tested by obtaining the proteinogram of untreated and denatured plasma. Electrophoresis strips, buffer and staining solution were purchased from Biosystems (Spain), other chemicals from Sigma (Spain). About $2 \mu \mathrm{L}$ of sample were applied on an cellulose acetate strip (ref. 19000), previously moistened with electrophoresis buffer (Buffer 1 for electrophoresis; ref. 20000). The strip was mounted on a frame and placed on an electrophoresis tank with two cubettes. The ends of the strip were checked to ensure that they were in contact with the electrophoretic buffer in each cubette. Electrophoresis was carried out at $200 \mathrm{~V}$ for $35 \mathrm{~min}$ (power source EF-657-N, Argemi, Spain). The strips were stained with amido black staining solution for electrophoresis (ref. 20009), in a rotative stirrer for $5 \mathrm{~min}$. After staining, they were rinsed four times with $45 \%$ methanol (ref. M3641) plus 10\% acetic acid (glacial; ref. A6283) in water (2 min in a rotative stirrer). They were then dehydrated (1 min in methanol, in a rotative stirrer). Finally, they were transferred to a cyclohexanone solution and kept for $10 \mathrm{~min}$ in a rotative stirrer. This solution was prepared by mixing $8.5 \mathrm{~mL}$ methanol, $1.4 \mathrm{~mL}$ acetic acid (glacial) and $0.1 \mathrm{~mL}$ glycerol (ref. G7893). Then, $9 \mathrm{~mL}$ of this mix were added to $261 \mathrm{~mL}$ of methanol, adding $30 \mathrm{~mL}$ of acetic acid (glacial). The cyclohexanone solution was discarded and remade each fortnight. The strips were applied to a glass plate and heated with an infrared lamp, until they were totally transparent, and they were left at room temperature for $2 \mathrm{~h}$ for complete drying.
Stained protein bands were read using an Automatic Electrophoresis Interactor BT-506 (Biotecnica, Rome).

\subsection{Cryopreservation protocol}

We diluted the samples 1:1 with Tes-Tris-Fructose extender, containing 10\% egg yolk and $4 \%$ glycerol [64]. We added the extender at the same temperature as the sample $\left(5^{\circ} \mathrm{C}\right.$ or $\left.37^{\circ} \mathrm{C}\right)$. The samples incubated at $37{ }^{\circ} \mathrm{C}$ were put in a glass with $100 \mathrm{~mL}$ of water at the same temperature before putting them at $5{ }^{\circ} \mathrm{C}$, in order not to cause an abrupt change. After being left at $5{ }^{\circ} \mathrm{C}$ for $2 \mathrm{~h}$, the samples were further diluted with the same extender down to $1000 \times 10^{6}$ sperms $/ \mathrm{mL}$ and packed in $0.25 \mathrm{~mL}$ French straws. Freezing was carried out using a programmable biofreezer (Planner MRII $^{\circledR}$ ), at $-20{ }^{\circ} \mathrm{C} / \mathrm{min}$ down to $-100{ }^{\circ} \mathrm{C}$, and then transferred to liquid nitrogen containers. Thawing was performed by dropping the straws into water at $65^{\circ} \mathrm{C}$ for $6 \mathrm{~s}$.

\subsection{Sperm analysis}

For motility assessment, $5 \mu \mathrm{L}$ of sample were diluted in $500 \mu \mathrm{L}$ of PBS (pH 7.4; ref. P3813). A $5 \mu \mathrm{L}$ drop was put on a prewarmed slide and covered with a coverslip. The sample (at least five fields) was examined with a phase contrast microscope (Nikon Labophot-2; negative contrast optics), with a warming stage at $37^{\circ} \mathrm{C}$. Analysis was carried out using a CASA system (Motility Analyzer v. 7.4G, Hamilton-Thorne Research ${ }^{\mathrm{TM}}$ ), and the following parameters were used for the study: total motility (\%; TM), progressive motility (\%; PM), average path velocity $(\mu \mathrm{m} / \mathrm{s}$; VAP), linearity $(\%$; LIN). A spermatozoon was considered motile when $\mathrm{VCL}>10 \mu \mathrm{m} / \mathrm{s}$, and progressive if VCL $>25 \mu \mathrm{m} / \mathrm{s}$ and STR $>80 \%$ (VCL-curvilinear velocity and STR - straightness, were also provided by the CASA). Detailed explanation of the descriptors of sperm movement is provided elsewhere [65]. We used the following configuration as displayed in the software setup: frames acquired, 20; frame rate at $25 \mathrm{~s}^{-1}$; minimum contrast, 10; minimum size, 9; Lo/Hi size gates, 0.9/2.1; Lo/Hi intensity gates, 0.4/1.6; non-motile head size, 9; non-motile brightness, 10; medium VAP value, 25; low VAP value, 10; slow cells motile, NO; threshold STR, 80. Thus, the image acquisition rate was 25 frames/s and the acquisition time was $0.8 \mathrm{~s}$.

Viability and acrosomal status assessments were carried out simultaneously using fluorescent probes (modified from Cheng et al. [66]). Samples (prefreezing and post-thawed) were diluted in PBS (1:100), and stained with prodidium ioide (PI; 
$25 \mu \mathrm{g} / \mathrm{L}$; ref. P4170) and PNA (peanut agglutinin; ref. L7381) conjugated with FITC $(1 \mu \mathrm{g} / \mathrm{mL})$. Then, they were kept $10 \mathrm{~min}$ in the dark before being analyzed with an epifluorescence microscope (Nikon Optiphot; $\times 400,450-490 \mathrm{~nm}$ excitation filter, $510 \mathrm{~nm}$ dichroicbeam splitter, $520 \mathrm{~nm}$ barrier filter). At least 100 cells were counted, discriminating between red (non-viable, acrosome intact), red-green (non-viable, acrosome damaged), green (viable, acrosome damaged) and non-stained (viable; acrosome intact) spermatozoa. For data analysis, we used the percentage of viable spermatozoa with intact acrosomes (non-stained cells). For brevity, we will refer to this parameter as viability.

\subsection{Statistical analysis}

Recovery after cryopreservation was calculated as the ratio between post-thawing and pre-freezing values (post-thawing/pre-freezing $\times 100$ ). For VAP and LIN, the correction proposed by Katkov and Lulat [67] was applied before calculating recovery (parameterxTM/ 100).

Data were normalized for variance (arc sine transformation for percentages and log transformation for other data), and analysed using factorial ANOVA, using pool as block, and plasma treatment (no plasma, plasma and denatured plasma) and incubation treatment $\left(32{ }^{\circ} \mathrm{C} 15 \mathrm{~min} ; 5{ }^{\circ} \mathrm{C} 15 \mathrm{~min} ; 5{ }^{\circ} \mathrm{C} 2 \mathrm{~h}\right.$; and $5{ }^{\circ} \mathrm{C} 6 \mathrm{~h}$ ), and their interactions as factors. Treatment groups (when the effect of a factor or interaction was significant) were compared using Tukey-Kramer multiple comparison for adjusted means.

\section{Results}

The proteinogram of the untreated and denatured plasma pools are shown in Fig. 1. Heat-inactivated

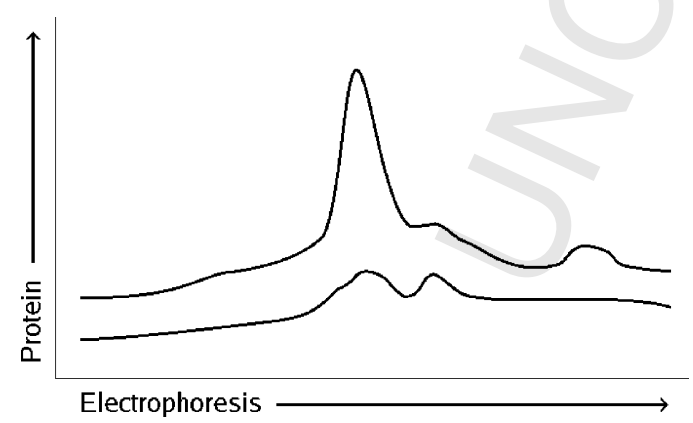

Fig. 1. Proteinograms of untreated (above) and denatured (below) seminal plasma. Both graphs have been displaced in the $y$-axis direction in order to notice the differences. plasma showed a clear reduction in the quantity of detectable protein.

The analysis of the statistical model (Table 1) showed that plasma treatment significantly affected sperm parameters after cryopreservation, and its recovery, but its effect was not significant in the initial and pre-freezing analysis (except for viability in the prefreezing analysis). However, the effect of incubation was noticeable even in the initial analysis, and it was evident in the pre-freezing, post-thawing and recovery analysis, when it affected most parameters. Nevertheless, we did not find any significant interaction between these two factors, apart from viability in the pre-freezing and post-thawing evaluations.

Comparison between plasma treatments (Table 2) showed no differences in the initial assessment. In the pre-freezing evaluation, viability of plasma treated samples was higher than in untreated samples. Postthawing and freezing-thawing recovery recorded a general significant decrease of quality values in untreated samples in comparison with plasma samples (except for LIN results). There were no significant differences between untreated and denatured plasma.

Table 1

Significance of each factor and interaction for each parameter

\begin{tabular}{|c|c|c|c|c|}
\hline Assessment & Parameter & Plasma & Incubation & Plasma $\times$ incubation \\
\hline \multirow[t]{5}{*}{ Initial } & $\mathrm{TM}$ & & & \\
\hline & $\mathrm{PM}$ & & & \\
\hline & VAP & & & \\
\hline & LIN & & & \\
\hline & Viability & & * & \\
\hline \multirow[t]{5}{*}{ Pre-freezing } & TM & & $* * *$ & \\
\hline & $\mathrm{PM}$ & & $* * *$ & \\
\hline & VAP & & $* * *$ & \\
\hline & LIN & & & \\
\hline & Viability & *** & $* * *$ & ** \\
\hline \multirow[t]{5}{*}{ Post-thawing } & $\mathrm{TM}$ & $* * *$ & $* * *$ & \\
\hline & PM & $* * *$ & $* * *$ & \\
\hline & VAP & $* * *$ & $* * *$ & \\
\hline & LIN & & $*$ & \\
\hline & Viability & $* * *$ & **** & **** \\
\hline \multirow[t]{5}{*}{ Recovery } & $\mathrm{TM}$ & $* *$ & $* * *$ & \\
\hline & PM & $* *$ & $* * *$ & \\
\hline & VAP & $*$ & $* * *$ & \\
\hline & LIN & & & \\
\hline & Viability & $* * *$ & $* * *$ & \\
\hline
\end{tabular}

TM: total motility; PM: progressive motility; viability: percentage of viable and acrosome-intact spermatozoa according to PI/PNA-FITC staining.

${ }^{*} P<0.05$.

** $P<0.01$.

**** $P<0.001$. 
Table 2

Variation in the analysed parameters according to plasma treatment

\begin{tabular}{|c|c|c|c|c|}
\hline Assessment & Parameter & No plasma & Plasma & Denatured plasma \\
\hline Initial & $\begin{array}{l}\text { TM }(\%) \\
\text { PM }(\%) \\
\text { VAP }(\mu \mathrm{m} / \mathrm{s}) \\
\text { LIN }(\%) \\
\text { Viability }(\%)\end{array}$ & $\begin{array}{l}57.90 \pm 2.87 \\
25.40 \pm 2.19 \\
49.50 \pm 7.39 \\
53.88 \pm 4.39 \\
80.46 \pm 1.10\end{array}$ & $\begin{array}{l}50.30 \pm 2.87 \\
20.85 \pm 2.19 \\
44.50 \pm 7.39 \\
59.62 \pm 4.39 \\
82.71 \pm 1.10\end{array}$ & $\begin{array}{l}54.00 \pm 2.87 \\
20.55 \pm 2.19 \\
48.88 \pm 7.39 \\
58.00 \pm 4.39 \\
80.43 \pm 1.18\end{array}$ \\
\hline Pre-freezing & $\begin{array}{l}\text { TM }(\%) \\
\text { PM }(\%) \\
\text { VAP }(\mu \mathrm{m} / \mathrm{s}) \\
\text { LIN }(\%) \\
\text { Viability }(\%)\end{array}$ & $\begin{array}{l}62.65 \pm 1.45 \\
21.07 \pm 1.01 \\
44.49 \pm 1.08 \\
42.92 \pm 1.51 \\
69.87 \pm 0.67^{\mathrm{a}}\end{array}$ & $\begin{array}{l}66.75 \pm 1.45 \\
22.70 \pm 1.01 \\
45.54 \pm 1.05 \\
41.90 \pm 1.46 \\
74.29 \pm 0.70^{b}\end{array}$ & $\begin{array}{l}67.75 \pm 1.45 \\
25.02 \pm 1.01 \\
46.83 \pm 1.08 \\
42.39 \pm 1.51 \\
74.63 \pm 0.68^{b}\end{array}$ \\
\hline Post-thawing & $\begin{array}{l}\text { TM }(\%) \\
\text { PM }(\%) \\
\text { VAP }(\mu \mathrm{m} / \mathrm{s}) \\
\text { LIN }(\%) \\
\text { Viability }(\%)\end{array}$ & $\begin{array}{l}42.69 \pm 1.48^{\mathrm{a}} \\
17.87 \pm 0.89^{\mathrm{a}} \\
46.05 \pm 1.21^{\mathrm{a}} \\
54.39 \pm 0.71 \\
47.69 \pm 0.56^{\mathrm{a}}\end{array}$ & $\begin{array}{l}55.06 \pm 1.53^{\mathrm{b}} \\
23.77 \pm 0.92^{\mathrm{b}} \\
53.22 \pm 1.27^{\mathrm{b}} \\
54.59 \pm 0.74 \\
54.87 \pm 0.59^{\mathrm{b}}\end{array}$ & $\begin{array}{l}52.43 \pm 1.44^{\mathrm{b}} \\
24.22 \pm 0.86^{\mathrm{b}} \\
53.68 \pm 1.19^{\mathrm{b}} \\
54.73 \pm 0.70 \\
54.38 \pm 0.56^{\mathrm{b}}\end{array}$ \\
\hline Recovery (\%) & $\begin{array}{l}\text { TM } \\
\text { PM } \\
\text { VAP } \\
\text { LIN } \\
\text { Viability }\end{array}$ & $\begin{aligned} 69.81 & \pm 2.98^{\mathrm{a}} \\
92.40 & \pm 9.85^{\mathrm{a}} \\
70.98 & \pm 5.66^{\mathrm{a}} \\
107.70 & \pm 30.57 \\
70.34 & \pm 1.02^{\mathrm{a}}\end{aligned}$ & $\begin{aligned} 84.43 & \pm 3.08^{\mathrm{b}} \\
137.40 & \pm 10.17^{\mathrm{b}} \\
98.64 & \pm 5.66^{\mathrm{b}} \\
138.43 & \pm 30.59 \\
74.65 & \pm 1.15^{\mathrm{b}}\end{aligned}$ & $\begin{aligned} 79.44 & \pm 2.90^{\mathrm{b}} \\
121.82 & \pm 9.59^{\mathrm{b}} \\
97.22 & \pm 5.55^{\mathrm{b}} \\
162.73 & \pm 29.99 \\
73.82 & \pm 1.01^{\mathrm{b}}\end{aligned}$ \\
\hline
\end{tabular}

Numbers are adjusted means \pm S.E.M. TM: total motility; PM: progressive motility; viability: percentage of viable and acrosome-intact spermatozoa according to PI/PNA-FITC staining. (a,b) Columns with different superscripts differ $P<0.05$.

Initial assessment did not render differences for incubation treatments. In general, pre-freezing results were in the sequence $5{ }^{\circ} \mathrm{C} 6 \mathrm{~h}<32{ }^{\circ} \mathrm{C} 15 \mathrm{~min}<5{ }^{\circ} \mathrm{C}$ $2 \mathrm{~h}<5^{\circ} \mathrm{C} 15 \mathrm{~min}$, and post-thawing results were in the sequence $\quad 32{ }^{\circ} \mathrm{C} \quad 15 \mathrm{~min}<5{ }^{\circ} \mathrm{C} \quad 15 \mathrm{~min}=5{ }^{\circ} \mathrm{C}$ $2 \mathrm{~h}=5{ }^{\circ} \mathrm{C} 6 \mathrm{~h}$. In the pre-freezing assessment, viability was lowest at $5{ }^{\circ} \mathrm{C} 6 \mathrm{~h}$. Freezing-thawing recovery results followed the sequence $32^{\circ} \mathrm{C} 15 \mathrm{~min}<5{ }^{\circ} \mathrm{C}$ $15 \min =5{ }^{\circ} \mathrm{C} 2 \mathrm{~h}<5{ }^{\circ} \mathrm{C} 6 \mathrm{~h}$ for TM, PM and VAP; for viability, $32{ }^{\circ} \mathrm{C} 15$ min rendered the lowest results, with no significant differences between the other treatments (Table 3).

The interaction between plasma and incubation treatments for the pre-freezing assessment of viability (Table 1) indicated that the protective effect of plasma was important in samples subjected to the $32{ }^{\circ} \mathrm{C}$ 15 min incubation (Fig. 2.1), but it was not significant for the rest of the treatments (comparing no plasma

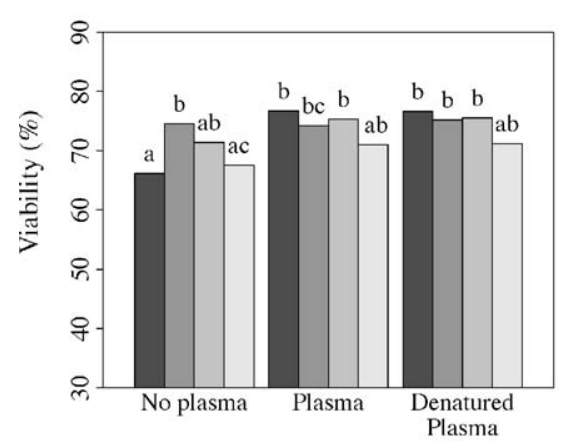

2.1 Pre-freezing

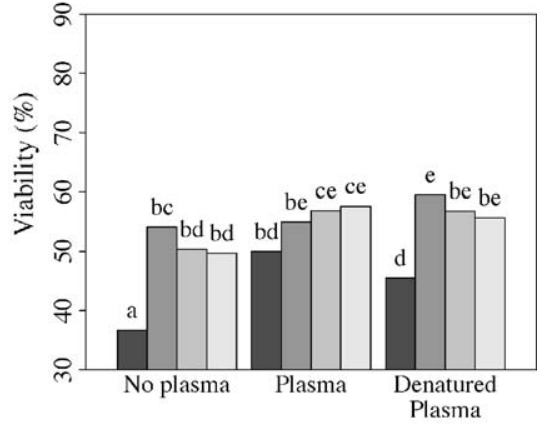

2.2 Post-thawing

Fig. 2. Variation of viability (adjusted means) according to plasma and incubation treatment (interaction analysis). Different letters indicate significant differences between treatments (plasma $\times$ incubation within pre-freezing or post-thawing analysis). Viability refers to the percentage of viable and acrosome-intact spermatozoa, according to PI/PNA-FITC staining. 
Table 3

Variation of the analysed parameters according to incubation treatment

\begin{tabular}{|c|c|c|c|c|c|}
\hline Assessment & Parameter & $32{ }^{\circ} \mathrm{C} 15 \mathrm{~min}$ & $5^{\circ} \mathrm{C} 15 \mathrm{~min}$ & $5^{\circ} \mathrm{C} 2 \mathrm{~h}$ & $5^{\circ} \mathrm{C} 6 \mathrm{~h}$ \\
\hline Initial & $\begin{array}{l}\text { TM }(\%) \\
\text { PM }(\%) \\
\text { VAP }(\mu \mathrm{m} / \mathrm{s}) \\
\text { LIN }(\%) \\
\text { Viability }(\%)\end{array}$ & $\begin{array}{l}52.00 \pm 3.31 \\
25.00 \pm 2.53 \\
55.50 \pm 8.54 \\
63.00 \pm 5.07 \\
79.68 \pm 1.27\end{array}$ & $\begin{array}{l}57.20 \pm 3.31 \\
22.60 \pm 2.53 \\
45.50 \pm 8.54 \\
56.00 \pm 5.07 \\
81.81 \pm 1.27\end{array}$ & $\begin{array}{l}57.13 \pm 3.31 \\
24.20 \pm 2.53 \\
53.50 \pm 8.54 \\
64.50 \pm 5.07 \\
84.95 \pm 1.27\end{array}$ & $\begin{array}{l}49.93 \pm 3.31 \\
17.27 \pm 2.53 \\
36.00 \pm 8.54 \\
45.17 \pm 5.07 \\
78.36 \pm 1.40\end{array}$ \\
\hline Pre-freezing & $\begin{array}{l}\text { TM }(\%) \\
\text { PM }(\%) \\
\text { VAP }(\mu \mathrm{m} / \mathrm{s}) \\
\text { LIN }(\%) \\
\text { Viability }(\%)\end{array}$ & $\begin{array}{l}63.40 \pm 1.67^{\mathrm{a}} \\
23.16 \pm 1.17^{\mathrm{a}} \\
45.26 \pm 1.21^{\mathrm{a}} \\
43.68 \pm 1.70 \\
73.14 \pm 0.39^{\mathrm{a}}\end{array}$ & $\begin{array}{l}72.89 \pm 1.67^{\mathrm{b}} \\
28.87 \pm 1.17^{\mathrm{b}} \\
49.21 \pm 1.21^{\mathrm{b}} \\
42.34 \pm 1.70 \\
74.62 \pm 0.78^{\mathrm{a}}\end{array}$ & $\begin{array}{l}67.53 \pm 1.67^{\mathrm{a}} \\
24.80 \pm 1.17^{\mathrm{a}} \\
47.36 \pm 1.25^{\mathrm{ab}} \\
42.81 \pm 1.76 \\
74.07 \pm 0.77^{\mathrm{a}}\end{array}$ & $\begin{array}{l}58.38 \pm 1.67^{\mathrm{c}} \\
15.73 \pm 1.17^{\mathrm{c}} \\
40.65 \pm 1.25^{\mathrm{c}} \\
40.80 \pm 1.75 \\
69.90 \pm 0.78^{\mathrm{b}}\end{array}$ \\
\hline Post-thawing & $\begin{array}{l}\text { TM }(\%) \\
\text { PM }(\%) \\
\text { VAP }(\mu \mathrm{m} / \mathrm{s}) \\
\text { LIN }(\%) \\
\text { Viability }(\%)\end{array}$ & $\begin{array}{l}34.38 \pm 1.80^{\mathrm{a}} \\
13.47 \pm 1.08^{\mathrm{a}} \\
40.86 \pm 1.55^{\mathrm{a}} \\
52.62 \pm 0.91^{\mathrm{a}} \\
44.04 \pm 0.66^{\mathrm{a}}\end{array}$ & $\begin{array}{l}56.62 \pm 1.66^{\mathrm{b}} \\
25.42 \pm 1.00^{\mathrm{b}} \\
51.14 \pm 1.32^{\mathrm{b}} \\
54.06 \pm 0.78^{\mathrm{ab}} \\
56.19 \pm 0.63^{\mathrm{b}}\end{array}$ & $\begin{array}{l}54.80 \pm 1.66^{\mathrm{b}} \\
24.93 \pm 1.00^{\mathrm{b}} \\
55.22 \pm 1.35^{\mathrm{bc}} \\
55.62 \pm 0.79^{\mathrm{b}} \\
54.68 \pm 0.65^{\mathrm{bc}}\end{array}$ & $\begin{array}{l}54.45 \pm 1.72^{\mathrm{b}} \\
23.98 \pm 1.03^{\mathrm{b}} \\
56.72 \pm 1.41^{\mathrm{c}} \\
56.00 \pm 0.82^{\mathrm{b}} \\
54.33 \pm 0.65^{\mathrm{c}}\end{array}$ \\
\hline Recovery (\%) & $\begin{array}{l}\text { TM } \\
\text { PM } \\
\text { VAP } \\
\text { LIN } \\
\text { Viability }\end{array}$ & $\begin{aligned} 56.55 & \pm 3.62^{\mathrm{a}} \\
65.76 & \pm 11.96^{\mathrm{a}} \\
47.39 & \pm 6.96^{\mathrm{a}} \\
118.95 & \pm 37.58 \\
61.77 & \pm 1.38^{\mathrm{a}}\end{aligned}$ & $\begin{aligned} 77.21 & \pm 3.35^{\mathrm{b}} \\
98.67 & \pm 11.07^{\mathrm{b}} \\
79.76 & \pm 5.97^{\mathrm{b}} \\
136.06 & \pm 32.25 \\
75.58 & \pm 1.15^{\mathrm{b}}\end{aligned}$ & $\begin{aligned} 80.24 & \pm 3.35^{\mathrm{b}} \\
123.43 & \pm 11.07^{\mathrm{b}} \\
92.40 & \pm 6.28^{\mathrm{b}} \\
96.30 & \pm 33.89 \\
74.04 & \pm 1.17^{\mathrm{b}}\end{aligned}$ & $\begin{aligned} 97.57 & \pm 3.47^{\mathrm{c}} \\
180.98 & \pm 11.47^{\mathrm{c}} \\
136.23 & \pm 6.66^{\mathrm{c}} \\
193.85 & \pm 35.98 \\
80.36 & \pm 1.19^{\mathrm{b}}\end{aligned}$ \\
\hline
\end{tabular}

Numbers are adjusted means \pm S.E.M. TM: total motility; PM: progressive motility; viability: percentage of viable and acrosome-intact spermatozoa according to PI/PNA-FITC staining. (a,b,c) Columns with different superscripts differ $P<0.05$.

and plasma treatments). Viability results were very similar between non-treated and denatured plasma treatments.

The study of the interaction in the post-thawing analysis showed more differences between untreated and denatured plasma (Fig. 2.2). Thus, untreated plasma rendered the highest results in the $32{ }^{\circ} \mathrm{C} 15 \mathrm{~min}$ treatment; however, in the $5{ }^{\circ} \mathrm{C} 15 \mathrm{~min}$ treatment, viability for untreated plasma and no plasma treatments were similar, being higher for denatured plasma. Interestingly, the trend in the $5{ }^{\circ} \mathrm{C}$ incubations was totally opposite for untreated (increasing with incubation time) and denatured (decreasing with incubation time) plasma, resulting in similar values between untreated plasma $5{ }^{\circ} \mathrm{C} 6 \mathrm{~h}$ and denatured plasma $5{ }^{\circ} \mathrm{C}$ $15 \mathrm{~min}$; however, no differences reached significance between different times and plasma treatments in the $5{ }^{\circ} \mathrm{C}$ incubations.

\section{Discussion}

The present study represents the first report on the effect of seminal plasma on epididymal spermatozoa in cervids, and possibly the only one reporting a positive effect of seminal plasma on cryopreservation of epididymal sperm too. We found significant improvements when incubating epididymal samples with seminal plasma upon incubating the samples alone. We want to emphasize that the most important and generalized differences were observed after cryopreservation, thus showing the importance of seminal plasma for the successful cryopreservation of this kind of samples. In fact, for some treatments, PM and LIN recovery after thawing were higher than $100 \%$. These apparently odd results are not surprising at all, considering that linearity parameters of sperm motility generally drop in the pre-freezing evaluation, as noted in a previous study [52], resulting in a comparatively higher percentage of progressive spermatozoa after thawing. Although differences between treatments were not outstanding (in general, around 5-10\%), they could be the expression of higher underlying changes are therefore important when the samples are subjected to stressful conditions, as in $\mathrm{AI}$.

Previous studies in other species have shown that seminal plasma supplementation helped sperm quality recovery after cryopreservation [31,32]. However, these studies used ejaculated sperm. In contrast, [17] reported negative results applying bovine seminal plasma to the cryopreservation of epididymal sperm from African buffalo, similarly to another study using only buffalo seminal plasma heparin binding protein [68]. Moreover, Cary et al. [69] found no improvement using equine seminal plasma for freezing epididymal spermatozoa 
from the same species. In our study, a clear beneficial effect has been demonstrated in red deer, at least in the quality parameters analyzed: motility and viability.

Furthermore, we applied several incubation treatments, in order to detect further differences between plasma treatments. Nevertheless, the study of the interactions between seminal plasma and incubation treatments showed that these interactions were limited to viability, in the pre-freezing and post-thawing analyses. On the whole, we observed a clear negative effect of the incubation at $32{ }^{\circ} \mathrm{C}$, possibly due to the double thermal change the samples underwent in this treatment (initially at $5{ }^{\circ} \mathrm{C}$, then $32{ }^{\circ} \mathrm{C}$ for incubation and $5{ }^{\circ} \mathrm{C}$ again, before freezing), whereas samples incubated at $5{ }^{\circ} \mathrm{C}$ were not submitted to temperature changes. In fact, the $32{ }^{\circ} \mathrm{C}$ treatment was used here not considering its practical use, but as a means of testing seminal plasma effects in a stressful environment. It is remarkable that the $5{ }^{\circ} \mathrm{C}$ incubation treatments showed a decreasing quality with longer incubation times in the pre-freezing treatment, but not in the postthawing treatment. One explanation is that a subpopulation of epididymal spermatozoa was sensitive to both long cooling times and to cryopreservation. Thus, this subpopulation would have been partly affected by the 2 and $6 \mathrm{~h}$ incubations, as seen in reflecting into the lower results in the pre-freezing analysis. However, cryopreservation would have totally affected that subpopulation, therefore equalling all the $5{ }^{\circ} \mathrm{C}$ treatments in the post-thawing analysis. This hypothesis should be considered in the light of recent studies highlighting the importance of considering the role of sperm subpopulations in the cryopreservation process $[52,54]$.

Many studies have noted that seminal plasma has not only enzymatic, but also non-enzymatic antioxidant properties [41,70], which would explain the general protective effect we have found using seminal plasma, even after denaturing most proteins. Moreover, the study of the interaction between plasma and incubation treatments, regarding viability (membrane and acrosome-intact spermatozoa) suggested that there would be some differences between untreated and denatured plasma. Although we did not find significant differences between untreated and denatured plasma, the different trends in the incubation time at $5{ }^{\circ} \mathrm{C}$ suggest that there may be a different effect. It could be due to membrane remodelling by thermolabile factors, as suggested by other studies [6,14,15]. However, a more in-depth analysis was beyond the scope of this study. It is necessary to carry out biochemical studies, determining the exact composition and the antioxidant activity, both enzymatic and non-enzymatic, of red deer seminal plasma (untreated and denatured).

In conclusion, supplementing epididymal samples obtained from red deer with seminal plasma from the same species was highly positive, especially considering cryopreservation. In general, denatured (heatinactivated) and untreated seminal plasma protected samples with similar efficiency. Therefore, extenders for epididymal samples from red deer or similar species might be improved by supplementing them with seminal plasma. Nevertheless, considering the risks and practical drawbacks associated to the direct use of seminal plasma [57,58], research should be aimed not only to improve seminal plasma application, but also to identify the protective mechanisms involved, and then to use non-animal additives to mimic these mechanisms inside the extender. The assessment of the biochemical composition of red deer seminal plasma and its variations deserves much effort. Besides, the analysis of its antioxidant properties would be of great interest, because of its importance in the maintenance of sperm quality. These enhancements would contribute to the management and conservation not only of red deer, but also of other cervids.

\section{Acknowledgements}

This study was supported by Junta de Castilla y León (Grant AB29) and the Spanish Ministry of Education and Science (Grant AGL2004-05904/GAN). The authors thank Juan José Martínez, César Gómez, Juan Carlos Peral, the Territorial Service of Environmental Affairs of León, and the gamekeepers of the hunting reserves of Picos de Europa, Mampodre and Ancares (León, Spain) for their collaboration in the collection of the samples used in this work; Ana Rocío Díaz for her help in the processing of the samples; and Jana Bernardo and Belén García for their help and advice with the proteinograms.

\section{References}

[1] Cseh S, Solti L. Importance of assisted reproductive technologies in the conservation of wild, rare or indigenous ungulates: review article. Acta Vet Hung 2000;48:313-23.

[2] Soler AJ, Garcia AJ, Fernandez-Santos MR, Esteso MC, Garde JJ. Effects of thawing procedure on postthawed in vitro viability and in vivo fertility of red deer epididymal spermatozoa cryopreserved at -196 degrees C. J Androl 2003;24:746-56.

[3] Esteso MC, Fernandez-Santos MR, Soler AJ, Garde JJ. Head dimensions of cryopreserved red deer spermatozoa are affected by thawing procedure. Cryo Lett $2003 ; 24: 261-8$. 
[4] Foote R. Fertilizing ability of epididymal sperm from dead animals. J Androl 2000;21:355.

[5] Manjunath P, Soubeyrand S, Chandonnet L, Roberts KD. Major proteins of bovine seminal plasma inhibit phospholipase A2. Biochem J 1994;303(Pt 1):121-8.

[6] Therien I, Moreau R, Manjunath P. Bovine seminal plasma phospholipid-binding proteins stimulate phospholipid efflux from epididymal sperm. Biol Reprod 1999;61:590-8.

[7] Manjunath P, Therien I. Role of seminal plasma phospholipidbinding proteins in sperm membrane lipid modification that occurs during capacitation. J Reprod Immunol 2002;53:109-19.

[8] Perez-Pe R, Grasa P, Fernandez-Juan M, Peleato ML, CebrianPerez JA, Muino-Blanco T. Seminal plasma proteins reduce protein tyrosine phosphorylation in the plasma membrane of cold-shocked ram spermatozoa. Mol Reprod Dev 2002;61:22633.

[9] Bergeron A, Crete MH, Brindle Y, Manjunath P. Low-density lipoprotein fraction from hen's egg yolk decreases the binding of the major proteins of bovine seminal plasma to sperm and prevents lipid efflux from the sperm membrane. Biol Reprod 2004;70:708-17.

[10] Chiu P, Chung M, Tsang H, Koistinen R, Koistinen H, Seppala $\mathrm{M}$, et al. Glycodelin-S in human seminal plasma reduces cholesterol efflux and inhibits capacitation of spermatozoa. J Biol Chem 2005;280:25580-9.

[11] Dott HM, Harrison RA, Foster GC. The maintenance of motility and the surface properties of epididymal spermatozoa from bull, rabbit and ram in homologous seminal and epididymal plasma. J Reprod Fertil 1979;55:113-24.

[12] Leblond E, Desnoyers L, Manjunath P. Phosphorylcholine-binding proteins from the seminal fluids of different species share antigenic determinants with the major proteins of bovine seminal plasma. Mol Reprod Dev 1993;34:443-9.

[13] Therien I, Bleau G, Manjunath P. Phosphatidylcholine-binding proteins of bovine seminal plasma modulate capacitation of spermatozoa by heparin. Biol Reprod 1995;52:1372-9.

[14] Therien I, Moreau R, Manjunath P. Major proteins of bovine seminal plasma and high-density lipoprotein induce cholesterol efflux from epididymal sperm. Biol Reprod 1998;59:768-76.

[15] Therien I, Soubeyrand S, Manjunath P. Major proteins of bovine seminal plasma modulate sperm capacitation by high-density lipoprotein. Biol Reprod 1997;57:1080-8.

[16] Harkema W, Colenbrander B, Engel B, Woelders H. Effects of exposure of epididymal boar spermatozoa to seminal plasma on the binding of zona pellucida proteins during in vitro capacitation. Theriogenology 2004;61:215-26.

[17] Herold FC, Aurich JE, Gerber D. Epididymal sperm from the African buffalo (Syncerus caffer) can be frozen successfully with AndroMed and with triladyl but the addition of bovine seminal plasma is detrimental. Theriogenology 2004;61:715-24.

[18] Tecirlioglu R, Lacham-Kaplan O, Trounson A. Effects of electrical stimulation and seminal plasma on the motility of mouse sperm. Reprod Fertil Dev 2002;14:471-8.

[19] Martins S, Miranda P, Brandelli A. Acrosome reaction inhibitor released during in vitro sperm capacitation. Int $\mathbf{J}$ Androl 2003;26:296-304.

[20] Sanz L, Calvete JJ, Mann K, Gabius HJ, Topfer-Petersen E. Isolation and biochemical characterization of heparin-binding proteins from boar seminal plasma: a dual role for spermadhesins in fertilization. Mol Reprod Dev 1993;35:37-43.

[21] Vadnais ML, Kirkwood RN, Tempelman RJ, Sprecher DJ, Chou K. Effect of cooling and seminal plasma on the capacitation status of fresh boar sperm as determined using chlortetracycline assay. Anim Reprod Sci 2005;87:121-32.

[22] Yeung W, Lee K, Koistinen R, Koistinen H, Seppala M, Ho P, et al. Roles of glycodelin in modulating sperm function. Mol Cell Endocrinol 2006.

[23] Petersen BH, Lammel CJ, Stites DP, Brooks GF. Human seminal plasma inhibition of complement. J Lab Clin Med 1980;96:58291.

[24] Gonzales GF. Function of seminal vesicles and their role on male fertility. Asian J Androl 2001;3:251-8.

[25] Gwathmey TM, Ignotz GG, Suarez SS. PDC-109(BSP-A1/A2) promotes bull sperm binding to oviductal epithelium in vitro and may be involved in forming the oviductal sperm reservoir. Biol Reprod 2003;69:809-15.

[26] Ignotz GG, Lo MC, Perez CL, Gwathmey TM, Suarez SS. Characterization of a fucose-binding protein from bull sperm and seminal plasma that may be responsible for formation of the oviductal sperm reservoir. Biol Reprod 2001;64:1806-11.

[27] Alghamdi AS, Foster DN, Troedsson MH. Equine seminal plasma reduces sperm binding to polymorphonuclear neutrophils (PMNs) and improves the fertility of fresh semen inseminated into inflamed uteri. Reproduction 2004;127:593-600.

[28] Barrios B, Perez-Pe R, Gallego M, Tato A, Osada J, MuinoBlanco T, et al. Seminal plasma proteins revert the cold-shock damage on ram sperm membrane. Biol Reprod 2000;63:1531-7.

[29] Ollero M, Perez-Pe R, Muino-Blanco T, Cebrian-Perez JA. Improvement of ram sperm cryopreservation protocols assessed by sperm quality parameters and heterogeneity analysis. Cryobiology 1998;37:1-12.

[30] Belibasaki S, Amiridis GS, Lymberopoulos A, Varsakeli S, Kouskoura T. Ram seminal plasma and fertility: results from an ongoing field study. Acta Vet Hung 2000;48:335-41.

[31] Maxwell WM, Evans G, Mortimer ST, Gillan L, Gellatly ES, McPhie CA. Normal fertility in ewes after cervical insemination with frozen-thawed spermatozoa supplemented with seminal plasma. Reprod Fertil Dev 1999;11:123-6.

[32] Garner DL, Thomas CA, Gravance CG, Marshall CE, DeJarnette JM, Allen CH. Seminal plasma addition attenuates the dilution effect in bovine sperm. Theriogenology 2001;56:31-40.

[33] Maxwell WM, Welch GR, Johnson LA. Viability and membrane integrity of spermatozoa after dilution and flow cytometric sorting in the presence or absence of seminal plasma. Reprod Fertil Dev 1996;8:1165-78.

[34] Arienti G, Carlini E, Nicolucci A, Cosmi EV, Santi F, Palmerini CA. The motility of human spermatozoa as influenced by prostasomes at various pH levels. Biol Cell 1999;91:51-4.

[35] Grizard G, Chevalier V, Griveau JF, Lannou DL, Boucher D. Influence of seminal plasma on cryopreservation of human spermatozoa in a biological material-free medium: study of normal and low-quality semen. Int J Androl 1999;22:190-6.

[36] Potts RJ, Notarianni LJ, Jefferies TM. Seminal plasma reduces exogenous oxidative damage to human sperm, determined by the measurement of DNA strand breaks and lipid peroxidation. Mutat Res 2000;447:249-56.

[37] Kovalski NN, de Lamirande E, Gagnon C. Reactive oxygen species generated by human neutrophils inhibit sperm motility: protective effect of seminal plasma and scavengers. Fertil Steril 1992;58:809-16.

[38] Balercia G, Armeni T, Mantero F, Principato G, Regoli F. Total oxyradical scavenging capacity toward different reactive oxygen species in seminal plasma and sperm cells. Clin Chem Lab Med 2003;41:13-9. 
[39] Zini A, Garrels K, Phang D. Antioxidant activity in the semen of fertile and infertile men. Urology 2000;55:922-6.

[40] Dawra RK, Sharma OP. Effect of seminal plasma antioxidant on lipid peroxidation in spermatozoa, mitochondria and microsomes. Biochem Int 1985;11:333-9.

[41] Strzezek J. Secretory activity of boar seminal vesicle glands. Reprod Biol 2002;2:243-66.

[42] Zini A, Fischer MA, Mak V, Phang D, Jarvi K. Catalase-like and superoxide dismutase-like activities in human seminal plasma. Urol Res 2002;30:321-3.

[43] Kankofer M, Kolm G, Aurich J, Aurich C. Activity of glutathione peroxidase, superoxide dismutase and catalase and lipid peroxidation intensity in stallion semen during storage at 5 degrees C. Theriogenology 2005;63:1354-65.

[44] Gavella M, Lipovac V, Vucic M, Rocic B. Superoxide anion scavenging capacity of human seminal plasma. Int J Androl 1996;19:82-90.

[45] Chen H, Chow PH, Cheng SK, Cheung AL, Cheng LY, O WS. Male genital tract antioxidant enzymes: their source, function in the female, and ability to preserve sperm DNA integrity in the golden hamster. J Androl 2003;24:704-11.

[46] Cassani P, Beconi MT, O’Flaherty C. Relationship between total superoxide dismutase activity with lipid peroxidation, dynamics and morphological parameters in canine semen. Anim Reprod Sci 2005;86:163-73.

[47] Potts R, Jefferies T, Notarianni L. Antioxidant capacity of the epididymis. Hum Reprod 1999;14:2513-6.

[48] Braun J, Torres-Boggino F, Hochi S, Oguri N. Effect of seminal plasma on motion characteristics of epididymal and ejaculated stallion spermatozoa during storage at 5 degrees C. Dtsch Tierarztl Wochenschr 1994;101:319-22.

[49] Martinez-Pastor F, Alvarez M, Martinez F, Garcia AJ, Anel E, Soler AJ, Boixo JC, Garcia-Macias V, Garde JJ, Anel L. Seminal parameters of Iberian red deer (Cervus elaphus hispanicus) and the effect of hybridation (hispanicus $\times$ scoticus) on its quality. In: Proceedings of the 15th International Congress on Animal Reproduction, vol. 1; 2004.p. 219.

[50] Soler AJ, Perez-Guzman MD, Garde JJ. Storage of red deer epididymides for four days at 5 degrees $\mathrm{C}$ : effects on sperm motility, viability, and morphological integrity. J Exp Zoolog Part A Comp Exp Biol 2003;295:188-99.

[51] Soler AJ, Garde JJ. Relationship between the characteristics of epididymal red deer spermatozoa and penetrability into zonafree hamster ova. J Androl 2003;24:393-400.

[52] Martinez-Pastor F, Garcia-Macias V, Alvarez M, Herraez P, Anel L, de Paz P. Sperm subpopulations in Iberian red deer epididymal sperm and their changes through the cryopreservation process. Biol Reprod 2005;72:316-27.

[53] Fernandez-Santos MR, Esteso MC, Soler AJ, Montoro V, Garde JJ. The effects of different cryoprotectants and the temperature of addition on the survival of red deer epididymal spermatozoa. Cryo Lett 2005;26:25-32.

[54] Martinez-Pastor F, Garcia-Macias V, Alvarez M, Chamorro C, Herraez P, Paz P, et al. Comparison of two methods for obtaining spermatozoa from the cauda epididymis of Iberian red deer. Theriogenology 2006;65:471-85.

[55] Zomborszky Z, Zubor T, Toth J, Horn P. Sperm collection from shot red deer stags (Cervus elaphus) and the utilisation of sperm frozen and subsequently thawed. Acta Veter Hungar 1999;47:263-70.

[56] Garde J, Garcia A, Ortiz N, Lopez A, Gallego L. Artificial insemination in Iberian deer (Cervus elaphus hispanicus) with frozen-thawed epididymal spermatozoa.. In: Proceedings of the 4th International Deer Biology Congress; 1998. p. $166-8$.

[57] Givens M, Waldrop J. Bovine viral diarrhea virus in embryo and semen production systems. Vet Clin North Am Food Anim Pract 2004;20:21-38.

[58] Guérin B, Pozzi N. Viruses in boar semen: detection and clinical as well as epidemiological consequences regarding disease transmission by artificial insemination. Theriogenology 2005;63:556-72.

[59] Richthoff J, Spano M, Giwercman YL, Frohm B, Jepson K, Malm $\mathrm{J}$, et al. The impact of testicular and accessory sex gland function on sperm chromatin integrity as assessed by the sperm chromatin structure assay (SCSA). Hum Reprod 2002;17:3162-9.

[60] Elzanaty S, Richthoff J, Malm J, Giwercman A. The impact of epididymal and accessory sex gland function on sperm motility. Hum Reprod 2002;17:2904-11.

[61] Rekkas C, Kokolis N, Belibasaki S, Tsantarliotou M, Smokovitis A. Effect of alpha-tocopherol on plasma testosterone and plasminogen activator activity or inhibition in ram spermatozoa. Theriogenology 2000;53:751-60.

[62] Goeritz F, Quest M, Wagener A, Fassbender M, Broich A, Hildebrandt TB, et al. Seasonal timing of sperm production in roe deer: interrelationship among changes in ejaculate parameters, morphology and function of testis and accessory glands. Theriogenology 2003;59:1487-502.

[63] Bruinink A, Tobler U, Halg M, Grunert J. Effects of serum and serum heat-inactivation on human bone derived osteoblast progenitor cells. J Mater Sci Mater Med 2004;15:497-501.

[64] Kaabi M, Paz P, Alvarez M, Anel E, Boixo JC, Rouissi H, et al. Effect of epididymis handling conditions on the quality of ram spermatozoa recovered post-mortem. Theriogenology 2003;60:1249-59.

[65] Boyers SP, Davis R, Katz D. Automated semen analysis. Curr Probl Obstet Gynecol Fertil 1989;12:172-200.

[66] Cheng F, Fazeli A, Voorhout W, Marks A, Bevers M, Colenbrander B. Use of peanut agglutinin to assess the acrosomal status and the zona pellucida-induced acrosome reaction in stallion spermatozoa. J Androl 1996;17:674-82.

[67] Katkov I, Lulat AG. Do conventional CAS A-parameters reflect recovery of kinematics after freezing? CASA paradox in the analysis of recovery of spermatozoa after cryopreservation. Cryo Lett 2000;21:141-8.

[68] Harshan H, Singh L, Arangasamy A, Ansari M, Kumar S. Effect of buffalo seminal plasma heparin binding protein (HBP) on freezability and in vitro fertility of buffalo cauda spermatozoa. Anim Reprod Sci 2005. Epub ahead of print; doi:10.1016/ j.anireprosci.2005.07.010.

[69] Cary JA, Madill S, Farnsworth K, Hayna JT, Duoos L, Fahning ML. A comparison of electroejaculation and epididymal sperm collection techniques in stallions. Can Vet J 2004;45:35-41.

[70] Gavella M, Lipovac V, Vucic M, Rocic B. Evaluation of ascorbate and urate antioxidant capacity in human semen. Andrologia 1997;29:29-35. 